\title{
İhsangazi Tarlalarından Soframıza Kültür Mirası Siyez Buğdayı
}

\author{
Sevinç KARABAK' (D) Rahmi TAȘCl' $\quad$ Vedat CEYHAN² \\ Kürșad ÖZBEK ${ }^{3} \quad$ Hilal YÜCE ARSLAN ${ }^{4}$ \\ 'Tarla Bitkileri Merkez Araștırma Enstitüsü Müdürlüğü, Ankara \\ 219 Mayıs Üniversitesi Ziraat Fakültesi, Samsun \\ ${ }^{3}$ Türkiye Milli Botanik Bahçesi Müdürlüğü, Ankara \\ ${ }^{4}$ Tohumluk Tescil ve Sertifikasyon Merkezi Müdürlüğü, Ankara
}

\begin{abstract}
*Sorumlu yazar e-mail (Corresponding author e-mail): sevinc.karabak@tarim.gov.tr
Geliș tarihi (Received): 09.07.2019

Kabul tarihi (Accepted): 19.07.2019

DOI: 10.21657/topraksu.655281
\end{abstract}

\section{Öz}

Bu çalıșmada; yerel bir çeșit olan Siyez buğdayının üretiminden tüketimine kadar olan sürecinin detaylı analiz ve yorumunu yapmak ve değer zincirinde yer alan aktörleri belirlemek amaçlanmıștır. Çalıșmada detaylı bir araștırma yapabilmek için monografik araștırma tekniği kullanılmıștır. Bu teknikte bilgiler anket yolu ile elde edilmiștir. Anket çalıșmaları 2014 yllında Kastamonu Ili İhsangazi ilçesinde 15 yerleșim yerinde (köy, mahalle) 32 üretici ve 44 tüketici ile yürütülmüștür. Üretilen Siyez buğdayının \%68'i hayvan beslemede \%32'si bulgur yapımında kullanılmaktadır. Üretilen bulgurun ise \%11'i evde tüketilmekte, \%85'i pazarlanmaktadır. Ortalama 31 yıllık çiftçilik deneyimine sahip üreticilerin yaklașık \%54'ünün elle serpme ekim yaptığı, sadece \%31'inin üst gübre kullandığı belirlenmiștir. Üst gübre kullanan üreticilerin \%70'inin elle serpme ile gübre attığı, tamamına yakınının hastalık ilacı kullanmadığı tespit edilmiștir. Ortalama verim 228 kg/da olarak belirlenmiștir. Üreticilerin büyük bir bölümü buğdayını 2-8 km uzaklıktaki taș değirmenlerde öğütmektedir. Bölgede yıllık kiși bașına 14.2 kg Siyez bulguru tüketilmektedir. Siyez buğdayı en çok yetiștirildiği ilçe olan İhsangazi'nin adıyla beraber anılmaktadır ve bölge için önemli bir gelir kaynağıdır. Yerel çeșitlerin korunması ve üreticilerin üretime devamlıı̆ı açısından koruma ve pazarlama stratejilerinin belirlenmesi önem tașımaktadır.

Anahtar kelimeler : Bulgur tüketimi, Siyez buğdayı, yerel çeșitler

\section{Cultural Heritage Siyez Wheat From the İhsangazi Farms to the Cuisine}

\begin{abstract}
The present study aimed to conduct a detailed analysis and give suggestions on Einkorn wheat -a type of local wheat- starting from its production until its consumption and to determine related actors in the value chain. Monography was utilized with a view to carrying out a comprehensive research. In this research method, the information was obtained through a survey. The survey was conducted in 2014 with the participation of 32 manufacturers and 44 consumers in 15 residential settlements (village, quarters) in the district of Insangazi which is located in the province of Kastamonu. $68 \%$ of the Einkorn wheat produced is used in animal feeding, while 32\% is used in making of bulgur. $11 \%$ of the bulgur produced is consumed in homes and $85 \%$ is placed on the market. It was found out that around $54 \%$ of the manufacturers with 31 years of experience on average in the field of farming uses
\end{abstract}


the broadcast sowing method, and only $31 \%$ of manufacturers uses the surface-applied manures. Of the manufacturers using surface-applied manures, it was observed that $70 \%$ utilizes broadcast sowing method in fertilizing the soil, and that almost none of them uses any pesticides. The average efficiency obtained was determined to be $228 \mathrm{~kg} / \mathrm{da}$. The majority of the manufacturers grinds the wheat at stone mills that are located at a distance of $2-8 \mathrm{~km}$ from their farms. $14.2 \mathrm{~kg}$ Einkorn bulgur per person is produced annually in the region. Einkorn wheat is named after the district with the same name and is a vital source of living in the region. Therefore, it bears significance to define the protection and marketing strategies in terms of the protection of local species and sustainability of their production by manufacturers.

Keywords: Consumption of bulgur, einkorn wheat, local species

\section{Gíriș}

Zengin bir biyoçeșitliliğe sahip olan Türkiye aynı zamanda birçok türün de gen merkezidir. Bu türlerden biri olan buğday, ekonomik değerinin yanı sıra sosyo-kültürel ve tarihi bir değer de tașımaktadır. Buğdayın en ilkel formu olarak bilinen ve tarihi yaklașık 10000 yıl öncesine dayanan Siyez(einkorn/Triticum monococcumL.) buğdayı bu kültürel mirasın önemli bir parçasıdır. Iza, Kaplıca, Kavulca olarak da adlandırılan Siyez ya da Einkorn (Triticum monococcum). Triticum boeoticum türünden yabani buğday türünün kültüre alınmıș formudur. Triticum dicoccum buğdayı ile birlikte erken dönemde kültüre alınan buğday türlerindendir. İlk kez Güneydoğu Anadolu bölgesinde yer alan Karacadağ'da evcilleștirildiği düșünülmektedir (Kimber ve Sears 1983).

Siyez kelimesi bazı yerlerde hem emmer hem de einkorn için kullanılmaktadır (Karagöz 1996, Ertug 2004, Giuliani vd., 2009). Çoğunlukla uzun boylu oldukları için yatan, gübreye tepkisi pek olmayan ve genelde yaprak hastalıklarına hassas çeșitler (Özberk vd. 2005) olarak bilinmektedir. Tek bașakçıkı olması ve sıkı kavuz yapısı ile hastalık ve zararlılara dayanıklı, kurak șartlarda ve fakir topraklarda rekabet gücü yüksek bir tür olan Siyez buğdayı, yüksek yağ içeriğine ve ekmeklik buğdaya göre daha fazla sarı lutein oranına sahiptir. Yaygın bir üretime sahip olmamakla birlikte, üretimi çoğunlukla geleneksel metotlarla yapılmaktadır. Daha çok bulgur ve hayvan yemi olarak değerlendirilmekte, taș değirmenlerde öğütülerek yapılan bulgur ekșili pilav, kuru pilav ve salçalı pilav șeklinde tüketilmektedir. Geleneksel ekmek yapımında kullanılmakla birlikte son yıllarda çok düșük oranlarda un ve eriștesi de yapılmaktadır.

Siyez buğdayı da en fazla Kastamonu ilinde üretilmektedir. Oldukça az miktarlarda Bolu, Sinop ve Samsun ilinde birkaç çiftçi tarafından ekimi devam ettirilmektedir. Kastamonu ili ìnsangazi ilçesi en fazla ekim alanına sahiptir ve bulgur için üretimi yapılmaktadır. Kastamonu Tarım ve Orman il Müdürlüğü 2014 yllı kayıtlarına göre Kastamonu'da

Çizelge 1. 2014 yılı Kastamonu Ili Siyez buğdayı ekim alanı ve bulgur üretimi

Table 1. Einkorn wheat cultivation area and bulgur production in Kastamonu province in 2014

\begin{tabular}{lcccc}
\hline İlçe Adı & Ekilen Alan (da) & Üretim (ton) & Bulgur (ton)* & \\
\hline İhsangazi & 5000 & 1250 & 225 & 900 \\
Seydiler & 750 & 187.5 & 112.5 & 53 \\
Merkez & 425 & 106.25 & 32 & 25 \\
Devrekani & 200 & 50 & 15 & 20 \\
Araç & 100 & 25 & 3 & 12.5 \\
Tașköprü & 100 & 25 & 7.50 & 1.80 \\
Daday & 75 & 18.75 & 10 & 10 \\
Ağlı & 40 & 10 & 405 & 1022.3 \\
Toplam & 6690 & 1672.5 & & \\
\hline
\end{tabular}

Kaynak: Kastamonu Tarım ve Orman II Müdürlüğü (2014)

*Bulgur Verimi \% 60 randımanla hesaplanmıștır. 
Çizelge 2. 2015 Yılı Kastamonu Ili Siyez buğdayı ekiliș alanı

Table 2. Kastamonu province einkorn wheat cultivation area in 2015

\begin{tabular}{lc}
\hline İlçe Adı & Ekilen Alan (da) \\
\hline İhsangazi & 6000 \\
Seydiler & 790 \\
Merkez & 530 \\
Devrekani & 200 \\
Tașköprü & 100 \\
Araç & 100 \\
Daday & 75 \\
Ağlı & 40 \\
Toplam & 7835 \\
\hline
\end{tabular}

Kaynak: Kastamonu Tarım ve Orman İı Müdürlüğü (2015)

1000 düzeyinde Siyez üreticisi bulunmaktadır. Bunun yaklașik 750 kadarı İhsangazi ilçesindedir. Siyez bulguru bu bölge halkı için geleneksel bir ürün özelliği tașımaktadır. Yöre halkı için önemli bir gelir kaynağı olmasına rağmen il içi ve il dıșı bitkisel üretim ve ticarette çok az bir paya sahiptir. 2014 yilında Kastamonu'da toplam 6690 da Siyez buğdayı ekilmiș ve 405 ton bulgur üretilmiștir. 2015 yılında ise ekim alanı 7835 dekara yükselmiștir. İhsangazi, merkez ve Seydiler ilçesinde 2014 yılına göre ekim alanlarının arttığı görülmektedir. 2015 yllında İhsangazi' de toplam ekim alanı 6000 dekara ulașmıștır (Çizelge 1, 2). Kastamonu'da ayrıca oldukça düșük miktarda çatal Siyez de /Triticum dicoccum) üretilmekte ve genellikle hayvan yemi olarak değerlendirilmektedir. İșleme zorlukları, sınırlı pazarlama imkanı ve talep yetersizliği, ürün ekiminin azalmasında kilit faktörlerdir. Emmer'in yoksul topraklara adapte olabilmesine ve düșük girdi intiyacına rağmen, pazar fırsatlarının yetersiz olması üretimi engelleyen önemli bir faktördür (Giuliani vd., 2009).

Son yıllarda sağıklı gıdalara ve yerel ürünlere olan talebin artması ile Siyez bulguruna da talebin arttığı görülmektedir. Ancak talep artıșına rağmen üretimde yeterince artıș sağlanamadığından piyasa değeri giderek yükselmekte ve tüketicinin alım gücünü zorlaștırmaktadır.

Bu çalıșmada öncelikle üretimden tüketime kadar olan sürecin analiz ve yorumunu yapmak, pazarlama fırsatları hakkında fikir üretmek, çeșidin çevresel, sosyo-ekonomik ve beslenme açısından sürdürülebilirliğini araștırmak, yeni politikaların geliștirilmesi için politika yapıcılara veri sağlamak amaçlanmıștır. Aynı zamanda çalıșmadan elde edilen veriler değer zinciri analizi araștırması için önemli bir kaynak olușturmuștur.
Bu çalıșma; Bioversity International tarafından küresel olarak, Tarım ve Orman Bakanlığı Tarımsal Araștırmalar ve Politikalar Genel Müdürlüğü tarafindan ulusal olarak yürütülen, UNEP ve FAO'nun uygulayıcı olduğu ve Küresel Cevre Fonu tarafından desteklenen, "Beslenme ve Gıda İcin Biyoçeșitilik Projesi (BFN)" kapsamında yapılan sosyo-ekonomik çalıșmaların bir bölümüdür.

\section{MATERYAL VE YÖNTEM}

BFN projesi kapsamında yapılan sosyoekonomik çalıșmalarda 41 adet yabani tür ve 2 adet yerel börülce ve yerel buğday çeșidinin üretiminden tüketimine kadar olan süreç detaylı olarak araștırılmıștır. Çalıșmada yerel buğday çeșidi olarak Siyez seçilmiștir. Bu kapsamda; Siyez buğdayı ile ilgili araștırma üretimin en fazla olduğu Kastamonu Illi İhsangazi ilçesinde yürütülmüștür.

Çalıșmada monografik araștırma tekniği kullanılmıștır. Monografi: sınırları belirlenmiș tek bir konu üstünde uygulanan bir araștırma tekniğidir. Kısaca sınırlı bir konunun, derinlemesine incelenmesidir. Bu teknikte bilgiler anket yolu ile elde edilmiștir. Aynı zamanda yerleșim yerleri ve pazarlarda ön bilgi toplama çalıșması yapılmıștır. Örnek sayısı ana kitleyi temsil edecek șekilde gayeli olarak seçilmiștir.

Anket çalıșmaları 2014 yılında Kastamonu Illi İnsangazi ilçesinde 15 yerleșim yerinde (köy, mahalle) 32 üretici ve 44 tüketici ile yürütülmüștür. Araștırmanın birincil verileri anket yolu ile elde edilen verilerden, ikincil verileri ise Kastamonu ve İhsangazi Gıda Tarım ve Hayvancılık II ve İlçe Müdürlüklerinden, sahada yapılan ön araștırmalar ile sağlanan verilerden ve literatür taramalarından olușmaktadır. 
Çalıșmanın amaçları doğrultusunda anketler ile:

- Yetiștirme tekniği, ișleme, pazarlama,

- Ticari çeșitlerle rekabet durumu,

- Tüketim șekli, miktarı, tüketim sıklığı,

- Üretimin sürdürülebilirliği,

- Üretici ve tüketicilerin biyoçeșitlilik ve çevresel farkındalıkları,

- Unutulmaya yüz tutmuș geleneksel bilgileri detaylı araștırımıștır.

Verilerin analizinde ağırıklı ortalamalar, frekans dağıımları, oransal dağılımlar gibi temel istatistikler kullanılmıștır. Yerel ve ticari çeșitlerin karșılaștırımasında ise elde edilen verilerin ortalamalarının karșılaștırıması yerine Siyez bulguru ve ticari bulgur çeșitlerinin medyanlarının karșılaștırıması amacıyla Mann-Whitney $U$ testi (Sokal ve Rohlf 1981; Özdamar, 2004; Özmutaf 2004) gerçekleștirilmiștir.

\section{BULGULAR VE TARTIȘMA}

Anket yapılan üreticilerin yaș ortalaması 51 olup, \%53'ü ilkokul, \%31'i ortaokul ve \%16'sı lise mezunudur. Ortalama hane halkı büyüklüğü 5.9 kiși olup, hane halkının \%49'u erkek, \%51'i kadın nüfusundan olușmakta ve \%77'si tarımla uğrașmaktadır. Üreticilerin tarımsal deneyimleri ortalamayaklașık 34 yıl, Siyezyetiștirme deneyimleri ise ortalama yaklașık 31 yıldır.

Ortalama ișletme büyüklüğü 90 dekar, parsel sayısı ortalama 21 ve toplam ekilen arazinin \%81'i mülk arazilerdir. Üreticilerin \%16'sının kendilerine ait arazisi bulunmamaktadır.

Anket yapılan Siyez üreticilerinin yaklașı \%44'ü sadece ev tüketimi için üretim yaparken \%56'sı hem ticari hem de ev tüketimi için üretim yapmaktadırlar. Son on yılda üreticilerin \%50'si Siyez ekim alanlarını değiștirmediklerini, \%34'ü arttırdıklarını ve \%16'sı ise azalttıklarını ifade etmișlerdir. Genel olarak büyük çoğunluğu on yıldır verimde değișiklik olmadığını belirtmiștir.

\section{Siyez buğdayının yetiștirme tekniği}

Bölgede siyez buğdayı kıraç alanlarda yetiștirilmektedir. Teknolojinin az kullanıldığı bu alanlarda 25 Ekim-7 Kasım arasında ekim yapılmakta ve üreticilerin \%54'ü elle serpme ekim yaparken, \%28'i mibzer ile ekmektedir. Üreticilerin \%18'i ise hem elle hem de mibzer ile ekim yapmaktadır.

Dekara ortalama olarak yaklașık $31 \mathrm{~kg}$ tohum atılmakta ve tamamı kendi ürettikleri tohumu kullanmaktadır. Üreticilerin \%69'u tohum ilaçlaması yapmamaktadır. Tohumluk fiyatları 1.21.5 TL/kg arasında değișmektedir.

Üreticilerin \%94'ü taban gübresi, taban gübresi atanların yaklașık \%33'ü ise üst gübre atmaktadır. Hiç gübre kullanmayanların oranı \%6'dır. Taban gübresi atanların \%63'ü kimyasal gübreler, yaklașık \%17'si ahır gübresi atarken, \%20'si her ikisini de kullanmaktadır. Genel olarak kompoze gübre tercih edilmekte ve dekara ortalama 21 kg atılmaktadır. Üreticilerin \%70'i elle gübre atmaktadır. Üst gübre olarak çimen tozu ve üre tercih edilmektedir.

Üreticiler hastalık ve zararlılarla mücadele için ilaç kullanmazken, yabancı ot ilaçlamasını sadece $\% 41$ 'i yapmaktadır.

Hasat dönemi 10 Temmuz-22 Ağustos arasında değișmektedir. Elle hasat yapanların oranı oldukça düșük olup genellikle biçerdöver ve harman makinası ile hasat yapılmaktadır. Çoğunluğu ticari çeșitlerden daha geç hasat yapmaktadır. Elde edilen ortalama verim $228 \mathrm{~kg} /$ da düzeyindedir. Türkiye genelinde Kan vd. (2011)'nın yapmıș olduğu çalıșmada yerel buğday hasadında biçerdöver, biçme, orak ve tırpan kullanıldığı ifade edilmiștir.

Üreticilerin \%47'si Siyez buğdayı üretiminde problem yașadıklarını belirtmiștir. Pazarlama problemi birinci sırada yer almakta olup bunu; yatma ve kuraklık problemleri, satıș fiyatının düșük olması, biçerdöver ile hasatta tane kaybı ve mazotun pahalı olması izlemektedir.

\section{Siyez buğdayının tasarruf șekli ve pazarlama}

Siyez buğdayının samanı hayvan beslemede, taneleri bulgur yapımında ve kanatlı hayvan beslemede kullanılmaktadır. Üretilen buğdayın sadece \%32'si bulgur yapılmaktadır (Șekil 1). Üreticilerin yaklașık \%68'i kalan buğdayı kiler, ambar ve evlerinin bir odasında muhafaza etmektedir. Siyez üretimi çoğunlukla hayvancilıkla uğrașan düșük gelirli küçük aile ișletmeleri tarafından devam ettirilmektedir. Özellikle dağlık alanlarda küçük ișletmelerde ev intiyacına yönelik üretim yapılmaktadır (Kan vd., 2011 ). 


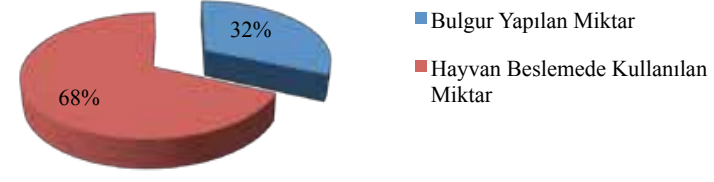

Șekil 1. Siyez buğdayının tasarruf șekli (\%)

Figure 1. The saving type of Einkorn wheat (\%)

Üreticilerin \%12.5'i Siyez buğdayını kendi değirmenlerinde, yaklașı \%27'si bulundukları köy içindeki değirmenlerde, $\% 60,5^{\prime} i$ ise ortalama 8 km uzaklıktaki köy dıșı değirmenlerde öğütmektedir.

Hasat sonrası harman, ayıklama, yıkama, pișirme gibi ön hazırlıklar tamamlandıktan sonra taș değirmenlerde öğütülen bulgur ev intiyacı ayrıldıktan sonra pazara sunulmaktadır. Üretilen bulgurun yaklașık \%11'i ev intiyacı için kullanılırken \%85'i pazarlanmaktadır (Șekil 2). Ürün pazara ilk olarak Ağustos ayında satıșa çıkarılmakta, pazarda șubat ayına kadar satıșta kalmaktadır.

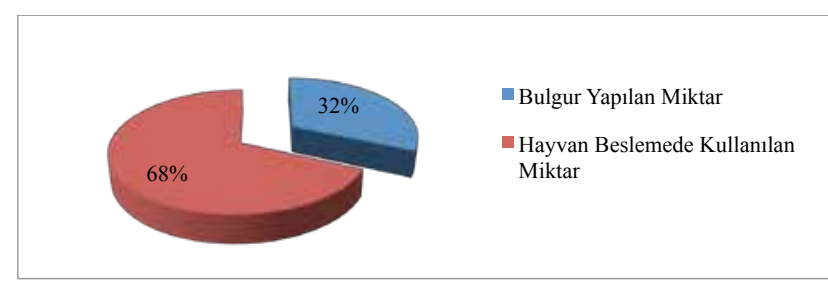

Șekil 2. Siyez bulgurunun tasarruf șekli

Figure 2. The way of saving einkorn bulgur
Pazarlama imkânlarının kısıtlı olması üreticilerin önemli problemlerinden biridir. Üreticilerin yaklașık yarısı ürettiği bulgurun bir kısmını pazarlamaktadır. Bulgur pazarlayan üreticilerin \%60'ı ürünü kendisi yerel pazara götürmektedir. Direk üreticiye satıș fiyatı ortalama 5 TL/kg'dır. Diğer üreticiler ise yerel pazarda toptancı veya tüccarlara satıs yapmaktadır. Aracı veya toptancıya satıș fiyatı ise yaklașık 4,8TL/ kg'dır. Fiyatlar piyasa șartlarına ve alıcıya göre olușmaktadır. Siyez bulgurunun pazardaki en düșük fiyatı 3,9 TL/kg, en yüksek fiyatı 6,5 TL/ kg'dır. Ticari buğday çeșitlerinden elde edilen bulgurun yerel pazarlardaki ortalama satıș fiyatı $1.5 \mathrm{TL} / \mathrm{kg}^{\prime} \mathrm{d}$ ır.

Siyezin ișlenmemiș buğday olarak satıș fiyatı yaklașık 0,86 TL/kg, ticari buğdayların ise yaklașık $0.56 \mathrm{TL} / \mathrm{kg}$ olduğu, Siyez buğdayının ticari buğdaya oranla \%53.6 oranında daha yüksek fiyatla satıldığı belirlenmiștir.

\section{Siyez ve ticari buğday çeșitlerinin bazı özellikler açısından karșılaștırılması}

Siyez üreticilerinin \%66'sı aynı zamanda ticari buğday çeșitlerini de ektiklerini ifade etmișlerdir. Siyez buğdayı ile ticari buğday çeșitleri bazı çeșit özellikleriaçısından karșılaștırıldığında; ticariçeșitlerin yatmaya karșı dayanıklılık ve bulgur veriminin Siyez bulguruna göre daha iyi olduğu, incelenen diğer özelliklere açısından Siyez buğdayının ticari çeșitlere göre daha iyi olduğu tespit edilmiștir (Çizelge 3).

Siyez buğdayı ve ticari buğday çeșitlerinin medyanlarının karșılaștıııması amacıyla

Çizelge 3. Siyez ve ticari çeșitlerin bazı kriterler açısından karșılaștırııması

Table 3. Comparison of Einkorn wheat and commercial wheat varieties in terms of some criteria

\begin{tabular}{lcccccc}
\hline \multirow{2}{*}{ Ceșit Özellikleri* } & \multicolumn{2}{c}{ Siyez Buğdayı } & \multicolumn{2}{c}{ Ticari Buğdaylar } & \multicolumn{2}{c}{ Toplam } \\
Verim & Ortalama & Std. Sapma & Ortalama & Std. Sapma & Ortalama & Std. Sapma \\
Hastalıklara karșı dayannıkılık & 1.800 & 0.847 & 2.033 & 0.809 & 1.917 & 0.829 \\
Zararlılara karșı dayanıkılık & 1.600 & 0.855 & 2.267 & 0.640 & 1.933 & 0.821 \\
Soğuğa karșı dayanıkııık & 1.600 & 0.855 & 2.233 & 0.679 & 1.917 & 0.829 \\
Kuraklığa karșı dayanıkılık & 1.933 & 0.850 & 2.233 & 0.626 & 1.933 & 0.800 \\
Pazar fiyatı & 1.600 & 0.740 & 2.267 & 0.583 & 2.100 & 0.681 \\
Yatmaya karșı dayanıklılık & 2.500 & 0.682 & 2.433 & 0.679 & 2.017 & 0.873 \\
Saman kalitesi & 1.733 & 0.868 & 2.000 & 0.830 & 1.867 & 0.853 \\
Saman verimi & 1.667 & 0.844 & 2.133 & 0.776 & 1.900 & 0.838 \\
Bulgur kalitesi & 1.467 & 0.860 & 2.367 & 0.490 & 1.917 & 0.829 \\
Bulgur verimi & 2.233 & 0.935 & 2.167 & 0.791 & 2.200 & 0.860 \\
\hline
\end{tabular}

*1:lyi, 2:Normal, 3:Kötü 
Çizelge 4. Mann-Whitney $U$ testi

Table 4. Mann-Whitney $U$ test

\begin{tabular}{lcccc}
\hline Çeșit Özellikleri & Mann-Whitney U & Wilcoxon W & Z & Asymp. Sig. (2-tailed) \\
\hline Verim & 379.000 & 844.000 & -1.116 & .265 \\
Hastalıklara karșı dayanıklıık & 244.000 & 709.000 & -3.234 & .001 \\
Zararılıara karșı dayanıklıık & 255.500 & 720.500 & -3.056 & .002 \\
Soğuğa karșı dayanıklılık & 259.500 & 724.500 & -2.993 & .003 \\
Kuraklığa karșı dayanıkılık & 338.000 & 803.000 & -1.829 & .067 \\
Pazar fiyatı & 216.500 & 681.500 & -3.682 & .000 \\
Yatmałya karșı dayanıklıık & 288.000 & 753.000 & -2.582 & .010 \\
Saman kalitesi & 370.000 & 835.000 & -1.266 & .206 \\
Saman verimi & 309.000 & 774.000 & -2.219 & .026 \\
Bulgur kalitesi & 171.500 & 636.500 & -4.376 & .000 \\
Bulgur verimi & 419.500 & 884.500 & -.489 & .625 \\
\hline
\end{tabular}

gerçekleștirilen Mann-Whitney $U$ testi analiz sonucunda verim, saman kalitesi ve bulgur verimi haricinde Siyez buğdayı ve ticari buğday arasında diğer özellikler açısından farklılık olduğu tespit edilmiștir (Çizelge 4).

Her iki tablo değerlendirildiğinde ticari çeșitlerin Siyez buğdayına göre yalnızca yatmaya karșı daha dayanıklı olduğu ( $\rho=0.01)$; verim, saman kalitesi ve bulgur verimi açısından herhangi bir farklılık bulunmadığı, incelenen diğer tüm değișkenler açısından ise Siyez buğdayının daha iyi olduğu ortaya çוkmaktadır.

\section{Üretime devam etme isteği ve biyoçeșitlilik}

Üreticilerin tamamı üretime devam etmeyi istediklerini belirtmișlerdir. Devam etme nedenlerini ise; bulgur için, gelir kaynağı, geleneksel bir ürün, fiyatı yüksek ve hayvan yemi olarak kullanmak için șeklinde sıralamıșlardır. Son beș yıl içinde Siyez buğday üretimine yönelik bir yatıım yapıp yapmadıkları sorulduğunda; yaklașık \%9'u paketleme ünitesi, ekim mibzeri ve sortex cihazı aldıklarını bildirmișlerdir. Büyük bir bölümü ileride çocuklarının devam ettirmesini istemelerine rağmen çocukların istekli olmadıklarını ifade etmișlerdir.

Son on yılda çevrelerinde biyoçeșitlilik açısından değișiklik olup olmadığı sorusuna üreticilerin \%50 si "evet/var" cevabını vermiștir. Bu değișiklikleri; iklim değiști (kıșlar azaldı, sıcaklık arttı) ve böcekler arttı șeklinde ifade etmișlerdir.

Kaybolan bitki türleri var mı sorusuna ise 3 kiși "Evet: Selvi kavağı, kendir ve burçak", kaybolan böcek ve hayvan türlerine \%25'i: "Alakarga, keklik, yerli sığır" cevabını vermiștir. Kaybolma nedeni olarak gübreleme, tarım ilaçları ve hastalıklar gösterilmiștir.

\section{Siyez bulgurunun tüketim miktarı ve sıklığı}

Araștırma sonuçlarına göre; yıllık Siyez bulguru tüketim miktarı hane bașına 84 kg, kiși bașına 14.2 kg olarak belirlenmiștir. Bölgede Siyez bulguru geleneksel bir ürün olması nedeniyle hane ve kiși bașına tüketim miktarı yüksek seviyelerdedir. Yapılan bazı araștırmalarda; Türkiye'de bulgur tüketiminin kiși bașına ortalama $12 \mathrm{~kg}$ olduğu ancak doğu bölgelerinde 23 kg'a kadar yükseldiği, batı bölgelerinde ise 7 kg'a kadar düștüğü belirlenmiștir (Bayram 2000, Bayram ve Öner 2002).

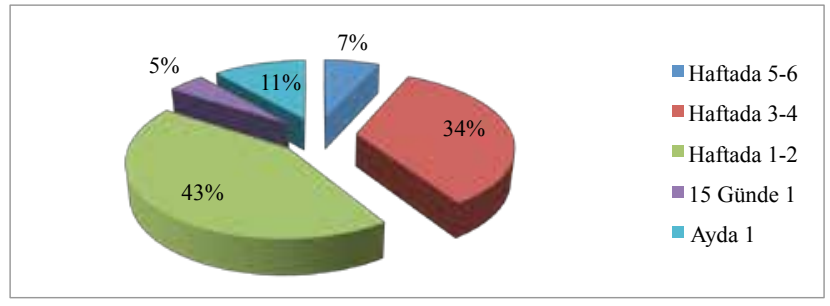

Șekil 3. Siyez bulgurunun tüketim sıklığı(\%)

Figure 3. Frequency of consumption of Einkorn bulgur (\%)

Tüketicilerin \%43'ü haftada 1-2 kez tüketirken, \%34'ü 3-4 kez tüketmektedir. Haftada 5-6 kez tüketenlerin oranı $\% 7$ seviyesindedir.

Tüketim șekli genellikle ekșili Siyez pilavı, kuru bulgur pilavı, çorba, dolma içi ve kısırdır. Ekșili Siyez pilavı tamamen yöreye has olup yenilebilir yabani otlarla yapılmaktadır.

\section{SONUÇLAR}

Siyez buğdayı hakkında gen kaynağı olarak kalitesi ve morfolojik özellikleri açısından birçok 
çalıșma bulunmaktadır. Ekonomik açıdan değerinin düșük olması sosyo-ekonomik çalıșmaların sınırlı kalmasına neden olmuștur. Ancak yerel çeșitler ve yenilebilir yabani türler, organik ürünler günümüzde giderek artan bir değer kazanmaktadır. Sağlıklı beslenme isteği, diyetler ve doğal ürünler tüketme arzusu tüketim alıșkanlıklarını da etkilemiștir. Bu çalıșma ile Siyez buğdayının değer zincirinde yer alan aktörleri belirlemek, üretimden tüketime kadar olan așamayı detaylandırmak, ticari çeșitlerle rekabet edebilme gücünü ortaya koymak amaçlanmıștır.

Kastamonu ilinde Siyez üretimi açısından büyük potansiyel olmasına rağmen üretim miktarı oldukça düșüktür. İhsangazi yöresinin diğer tarım ürünlerinin ekimi için elverișsiz olması, kuraklığa ve verimsiz toprağa dayanıklı olan Siyez buğdayını ilçe için en önemli tarım ürünü haline getirmiștir (Zengin, 2015).

Siyez buğdayı İhsangazi ilçesi için önemli bir kültür mirası, geleneksel bir gıda ve gelir kaynağıdır. Birçok yerde İhsangazi Siyez buğdayı olarak anılmasının en önemli nedeni üretiminin en fazla bu ilçede yapılmasıdır. Birkaç yıl öncesine kadar ilçede festivaller, sosyal aktiviteler düzenlenmiș ve tanıtımına ağırlık verilmiștir. Görsel basının tanıtım ve tüketimde oldukça etkili olduğu görülmüștür.

Siyez yetiștiriciliği diğer yerel çeșitlerde olduğu gibi daha çok dağlık ve küçük alanlarda yapılmaktadır. Bu nedenle teknoloji kullanımı oldukça düșüktür. Ekimi, bakımı, harmanı elle yapılmakta ve taș değirmenlerde öğütülerek bulgur elde edilmektedir. Kastamonu'da Seydiler ilçesinde bir adet bulgur fabrikası bulunmaktadır. Fabrikada un, eriște gibi farklı ürünler de üretilmeye bașlanmıștır.

Siyez üreticilerinin en önemli problemi pazarlama imkânlarının kısıtı olmasıdır. Yerel pazarlarda ürünü tüketiciye direk kendileri satmaktadır. Bir kısmı aynı zamanda yerel pazarda aracı-toptancılara da satıș yaptıklarını ifade etmișlerdir. Üretimin sınırlı olması büyük pazarlarda ürünün yer almasına ve talebi karșılayamamasına sebebiyet vermektedir. Hayvan yemi olarak kullanılan miktarın bir kısmı bulgur üretimine aktarılabilir ve üreticiler yerel çeșit ekimine teșvik edilebilir ise bulgur üretiminde artıș sağlanabilecektir.
Ticari çeșitlere oranla ișlenmiș ürün olarak üreticiye daha fazla gelir getirmektedir. Ayrıca ticari çeșitlere oranla daha az girdi kullanıldığından, üretim maliyeti daha düșüktür. Siyez ve ticari buğday çeșitleri çeșit özellikleri açısından karșılaștırıldığında Siyezin yatma problemi ve pazarlama fırsatları dıșında daha fazla öne çıktığı görülmüștür. Yatma problemi ile ilgili olarak yetiștirme tekniği konusunda detaylı araștırmalara intiyaç bulunmaktadır. Fakir topraklarda iyi performans göstermesi daha az ilaç ve gübre kullanımı nedeniyle organik ürün yetiștiriciliğine oldukça yatkındır. Bölgede 2-3 üretici dıșında organik üretim yapan ve sertifika alan üretici bulunmamaktadır. Bazı pazarlarda Siyez bulguru yüksek fiyatlarla organik ürün stantlarında yer almakta ancak sertifikası bulunmamaktadır. Organik ürün yetiștiriciliği içinde yerel çeșitlerin kullanılabilirliği araștırılması gereken bir diğer husustur.

Üreticilerin çoğunluğu Siyez buğdayı üretimine devam etmeyi istemektedirler ancak üretimi arttırmaya yönelik bir yatırım planları bulunmamaktadır.

İhsangazi ilçesinde Siyez bulguru oldukça sık ve yüksek miktarda tüketilmektedir. Tüketiciler tarafından geleneksel bir gıda ve diğer bulgurlara nazaran daha lezzetli olduğu için çok tüketildiği vurgulanmıștır. Yöreye has olan ekșili bulgur pilavı en fazla tüketilen yemektir.

Siyez yetiștiricileri son ylllarda çevrelerinde biyoçeșitlilik açısından birtakım değișiklikler olduğunu, bazı bitki ve hayvan türlerinin yok olduğunu ifade ederken böcek popülasyonunun arttığını belirtmișlerdir. Bunlara neden olarak tarımda kimyasal kullanımını göstermișlerdir. Son on yıl içinde iklimde de değișiklikler olduğu, sıcaklıkların arttığı, kıșların daha kısa geçtiği aktarımıștır. Ancak bu durumun Siyez buğdayı üretimine etkisi konusunda fikir beyan etmemișlerdir.

Bölgede Siyez yetiștiriciliği gittikçe daha cazip hale gelmektedir. Ancak pazarlama imkânlarının kısıtlı olması çözüm bekleyen bașlıca problemdir.

Siyez buğdayının önemli bir gen kaynağı ve bir kültür mirası olması; korunmasına, üretimi arttırıcı ve alternatif pazarlama stratejilerinin geliștirilmesine intiyaç duyulmaktadır. Bu stratejilerin aynı zamanda tüm yerel çeșitleri kapsaması önem arz etmektedir. 


\section{TEȘEKKÜR}

Araștırmanın gerçekleștirilmesinde emeği geçen "Gıda ve Beslenme için Biyoçeșitlilik Projesi" ekibine, Kastamonu il ve Ilıçe Tarım ve Orman Müdürlüklerine ve Siyez buğdayı üreticilerine teșekkür ederiz.

\section{KAYNAKLAR}

Ertug F (2004). Recipes of old tastes with einkorn and emmer wheat. TÜBA-AR 7:77- 188.

Giuliani A, Karagöz A, Zencirci N (2009). Emmer (Triticum dicoccon) production and market potential in marginal mountainous areas of Turkey. Mountain Research and Development, 29 (3): 220-229.

Kan M, Küçükçongar M, Keser M, Mourgonov A, Kaya Y, Dönmez E, Özbek K, Karabak S, Tașçı R, Ulucan O, Çakmak M, Yüksel S, Karadaș K, Denizer B (2011). The diversity of wheat land races in Turkey and their potential to use in breeding, 3-4 October 2011 , Bakü, Azerbaycan.

Karagöz A (1996). Agronomic practices and socioeconomic aspects of emmer and einkorn cultivation in Turkey. In Padulosi, S., K. Hammer and J. Heller (eds). Hulled Wheat. Promoting the Conservation and Use of Underutilized and Neglected Crops, 4, 172-177. Proceedings of the First
International Workshop on Hulled Wheats, Castelvecchio Pascoli, Tuscany, Italy 1995. Rome: International Plant Genetic Resources Institute.

Kimber G, Sears ER( 1 983). Assignment of genome symbols in the Triticea. In Proceedings of the 6th International Wheat Genetic Symposium', (S. Sakamoto, ed.), Plant Germplasm Institute, Kyoto University, Kyoto, Japan, 1 195-1 196.

Özberk I, Özberk F, Atlı A, Cetin L, Aydemir T, Keklikci Z, Önal MA, Braun HJ (2005). Durum wheat in Turkey; yesterday, today and tomorrow. durum wheat breeding: current aproaches and future strategies. (Ed) Royo C, Nachit,MN, Difonzo N, Araus JL, Pfeiffer WH, Slafer GA, Chapter: 33. The Howard Press İnc., USA. p. 1049.

Özdamar K (2004). Statistical data analysis with package programs: I (in Turkish). Kaan Kitabevi, Genișletilmiș 5. Bası, Eskișehir, 279-340, 487- 504.

Özmutaf NM (2004). Introduction to biostatistics (in Turkish), Ege Üniversitesi Yayınları, İzmir, 186-190.

Sokal RR, Rohlf FJ (1981). Biyometry. 2nd Ed., W. H. Freeman Com., San Francisco, 429-432.

Zengin G (2015). Bazı ilkel buğdaylarda kalite parametrelerinin belirlenmesi üzerine bir araștırma. Selçuk Üniversitesi Gıda Mühendisliği, Yüksek lisans tezi, Konya. 